\title{
Analysis of factors that characterize health impairment in patients with chronic respiratory failure
}

\author{
M. Carone*, G. Bertolotti**,, F. Anchisi*, A.M. Zotti**, C.F. Donner*, P.W. Jones*** on behalf of the \\ "Quality of Life in Chronic Respiratory Failure Group"
}

Analysis of factors that characterize health impairment in patients with chronic respiratory failure. M. Carone, G. Bertolotti, F. Anchisi, A.M. Zotti, C.F. Donner, P.W. Jones. C)ERS Journals Ltd 1999.

ABSTRACT: This study was designed to identify a core set of items that may characterize impaired health in chronic respiratory failure (CRF) since none of the questionnaires commonly used to measure impaired health in patients with $C R F$ were developed for use in such patients.

Questionnaire items, identified from several sources, were administered to 92 patients with stable severe chronic hypoxia or hypercapnia, together with physiological measures of disease severity, the Sickness Impact Profile (SIP) and the St George's Respiratory Questionnaire (SGRQ).

Of the 152 items identified, only 28 correlated with patients' perceptions of overall health and were also independent of age, sex, disease or type of treatment and did not show floor or ceiling effects. Principal components analysis identified three specific factors: "daily activities", "cognitive function", and "invalidity". The total score for the whole 28-item set correlated with other measures of disease activity, including SGRQ ( $r=0.86)$ and SIP $(r=0.70)$, but not spirometry. The interquartile range of the 28-item set was wider than that of the SGRQ or the SIP.

This study characterized two areas of health impairment in chronic respiratory failure that had not previously been identified: effects of impaired cognitive function on daily life, and a sense of invalidity. The measurements properties of this 28 -item set suggest that it may be a more discriminative instrument for patients with chronic respiratory failure than existing questionnaires.

Eur Respir J 1999; 13: 1293-1300.
"Salvatore Maugeri" Foundation, IRCCS, *Division of Pulmonary Disease, **Psychology Unit, Rehabilitation Institute of Veruno (NO) and ${ }^{+}$Rehabilitation Institute of Tradate (VA), Italy and ***St. George's Hospital Medical School, Division of Physiological Medicine, London, UK.

Correspondence: M. Carone, Fondazione "Salvatore Maugeri", IRCCS, Istituto di Riabilitazione, Divisione di Pneumologia, Via Revislate 13, 28010 Veruno (NO), Italy, Fax: 390322830294

Keywords: Chronic obstructive pulmonary disease

chronic respiratory failure

health status measurement

kyphoscoliosis

quality of life

Received: January 11998

Accepted after revision December 261998

M. Carone was supported, in part, by a "short term fellowship grant" from the Italian National Research Council (CNR).
Chronic obstructive pulmonary disease (COPD) and kyphoscoliosis frequently lead to chronic respiratory failure (CRF), a condition in which patients present with an arterial oxygen tension $\left(\mathrm{Pa}_{\mathrm{a}} \mathrm{O}_{2}\right) \leq 7.3 \mathrm{kPa}$ and/or an arterial carbon dioxide tension $\left(P \mathrm{a}, \mathrm{CO}_{2}\right)>6.6 \mathrm{kPa}$ [1]. These diseases are incurable and often inexorably progressive. Treatment, long-term oxygen therapy (LTOT) and/or overnight mechanical ventilation, is directed mainly towards minimization of patients' symptoms and improvement in health. Measurements normally used as an index of functional damage and/or improvement (e.g. spirometry and blood gas analysis) correlate poorly with reported impairment of physical function or overall health status (health-related quality of life $(\mathrm{QoL}))[2,3]$ and hence provide an incomplete picture of impaired health. The impact of disease on patients' health, daily life and wellbeing must be measured directly from the patients themselves, by means of validated health status questionnaires [4], which fall into two broad categories: general health and disease-specific measures.

General health questionnaires express a measure of the disturbance to health of a wide range of diseases. However, they were not designed specifically for chronic respiratory diseases and may not be adequately sensitive to clinically significant changes in health following treatment $[5,6]$.
Three generic instruments have been used in severe respiratory diseases, the Sickness Impact Profile (SIP) [7], the short form of the Medical Outcome Study Questionnaire (SF-36) [8] and the Nottingham Health Profile (NHP) [9]. The SIP is a valid measure of impaired general health in chronic airflow limitation, particularly in patients with a forced expiratory volume in one second (FEV1) $<50 \%$ predicted $[6,10,11]$, although SIP scores have not been shown to correlate with hypoxaemia, a feature of severe respiratory failure [12-14]. In contrast, hypoxia has been reported to correlate with scores from a disease-specific questionnaire [14]. The SF-36 has been applied to severe respiratory patients in two different studies. Simonds and ElLIOTT [15] studied patients with hypercapnic CRF caused by either obstructive or restrictive diseases. SMITH and SHNEERSON [16] administered the SF-36 to a group of severe acute respiratory patients $1 \mathrm{yr}$ after successful discharge from the intensive care unit. The scores were clearly different from those of healthy subjects, but formal tests of the discriminative properties of the SF-36 have not been performed in patients with respiratory failure.

The NHP has been used in chronic airway obstruction [9, 17-19], but with a lower level of sensitivity to health status impairment compared to disease-specific 
questionnaires such as the St George's Respiratory Questionnaire (SGRQ) [19] and the Chronic Respiratory Questionnaire (CRQ) [18]. The NHP and the SF-36 have been used in the same group of severe chronic airflow limitation patients on home oxygen therapy [17]; many domains in the two questionnaires did not correlate and so the authors suggested the use of these two questionnaires together until more experience is gained.

Disease-specific measures focus on a specific disease and its treatment and should therefore be more sensitive than the general health questionnaires. There are two main disease-specific measures, the CRQ [20] and the SGRQ [21]. Both were developed in patients with moderate disease and not in those with the most severe level of disease. The CRQ has been applied to patients with a mean FEV1 of $39 \%$ pred, but blood gas levels were not reported and so it is not clear whether or not these patients had CRF [22]. The SGRQ has been used in patients with respiratory failure due to COPD and shown to correlate with hypoxia, but not with hypercapnia [14]. Although the SGRQ appears to be valid for use in CRF and sensitive to changes following treatment [23], neither it nor the CRQ were developed in severe CRF patients. It is possible that such patients lie at the extremes of the usable scoring range of these questionnaires. This may be important, especially in long-term follow-up studies, since these questionnaires may not be able to detect deterioration over time. Furthermore, both questionnaires were developed in patients with COPD, but many patients with lung disease severe enough to require long-term ventilatory support and/or oxygen therapy have other diseases as well, such as kyphoscoliosis.

It was felt important to identify the factors that determine impaired health status in CRF and, particularly, to test for effects that may be specific to CRF, such as the effects of hypoxia on cognitive function in daily life, and address issues of dependency upon carers caused by the severe disability that CRF patients often experience. The aim of this study was to identify a core set of questionnaire items common to CRF patients irrespective of age, sex and the disease underlying the patient's CRF.

\section{Methods}

\section{Item selection}

A series of items were identified through several methods: 1) review of published papers; 2) semistructured interviews with patients; and 3) interviews with health professionals. This process produced 220 items which were then assessed for acceptability and style by showing the set to patients with CRF $(n=39)$, as well as to the nurses $(n=12)$ and doctors $(n=7)$ responsible for their care. Sixtyeight items were removed from further analysis since they were found to be unacceptable to the patients or difficult to understand. The remaining 152 items covered a wide range of areas of life relevant to severe respiratory disease including: respiratory and general symptoms $(n=15)$; activities which cause breathlessness $(n=19)$; activities that patients are no longer performing because of breathlessness $(n=19)$; beliefs, attitudes and expectations related to ill-health $(n=52)$; neuropsychological deficits $(n=20)$; employment $(n=7)$; and social life $(n=20)$. The item response option was dichotomous (true/false) for 124 items. Patients were required to respond "True", "False" or "Not applicable" to 20 items. Multiple category scales were used for eight items. Seventy of the 152 items were gleaned from previously published questionnaires. In particular, 10 items were drawn from the SIP, 11 from the Respiratory Illness Opinion Survey [24], two from the CRQ, 30 from the SGRQ and 17 from both the CRQ and SGRQ. All questionnaire items were generated initially in English, translated into Italian and then backtranslated into English to ensure that the original meaning of the items had been conveyed correctly in Italian.

\section{Patients}

Ninety-two patients with severe COPD or kyphoscoliosis were studied. All patients were recruited from respiratory medicine outpatient clinics at the "Salvatore Maugeri" Foundation Rehabilitation Institutes of Veruno, Cassano Murge, Gussago and Tradate. All patients were on LTOT or overnight home mechanical ventilation (HMV), some via a tracheostomy and others through a nasal mask. The protocol was approved by the local Ethical Committee and all patients were asked for and gave informed consent. Table 1 shows their anthropometric and pathophysiological data.

\section{Study design}

Patients were enrolled consecutively in the study. Pulmonary function tests, including residual volume, were performed in all but the tracheostomized patients according to European Community guidelines [25]. The patients also performed a 6-min walking distance (6-MWD) test [26, 27]. They were told that they could slow down or stop as necessary. Standard encouragement was given every $30 \mathrm{~s}$ [28]. The test was repeated three times and the third measurement used for analysis, to minimize learning effects $[26,29]$. A telemetric method was used to monitor electrocardiography and cardiac frequency. The subjects performed the test breathing supplemental oxygen at a flow rate that avoided exercise desaturation. Oxygen was administered by means of a portable source of liquid oxygen (Freelox portable unit; Vitalaire, Turin, Italy).

The patients completed the 152-item set as well as the Medical Research Council Dyspnoea Scale [30], a depression scale (Questionnaire of Depression) [31], one for anxiety state (state-trait anxiety inventory (STAI-X1))

Table 1. - Anthropometric and pathophysiological data according to diagnostic group

\begin{tabular}{lccc}
\hline & COPD & Kyphoscoliosis & p-value* \\
\hline Males n & 56 & 5 & $<0.001$ \\
Females n & 19 & 12 & $<0.001$ \\
Age yrs & $66 \pm 7$ & $58 \pm 6$ & NS \\
FEV1 \% pred & $35 \pm 15$ & $37 \pm 13$ & NS \\
6MWD m & $279 \pm 102$ & $253 \pm 97$ & NS \\
\hline
\end{tabular}

Data are presented as mean \pm SD. COPD: chronic obstructive pulmonary disease; FEV1: forced expiratory volume in one second; 6MWD: 6-min walking distance. *: Chi squared test using Fisher's exact test. Ns: not significant at $\mathrm{p}>0.05$. 
[32], the SIP, and the SGRQ. They also indicated their overall and respiratory health using two 5-point scales. These two scales each had five categories: "very good"; "good"; "satisfactory"; "poor"; and "very poor". Presentation of the different questionnaires was randomized between patients to reduce the likelihood of a "response set".

\section{Item analysis}

The purpose of this analysis was to explore the relationships between each question and the different demographic and disease-related variables. The first step was to identify those questions which were common and important to the majority of patients with CRF.

Response rate. The response rate for each item was examined to identify responses that lay in the lower or upper response range.

Age effect. Items that had a Spearman's correlation coefficient for ranked data $p<0.05$ (corresponding to $\rho=$ 0.21 for the number of patients included in this study) were regarded as being age related.

Sex effect. In order to identify items related to the sex of patients, the criterion used was a Chi-squared test with Fisher's exact test analysis, $\mathrm{p}<0.05$.

Disease effect. In order to examine the association between each item and the underlying diagnosis (COPD or kyphoscoliosis), a Chi-squared with Fisher's exact test analysis was used. To identify all the items that were influenced, even weakly, by the underlying diagnoses, a level of significance of $\mathrm{p}<0.05$ was used.

Treatment effect. The treatment of CRF ranges from LTOT to HMV. In order to test for an association between treatment type and the response to each item, a Chi-squared test with Fisher's exact test analysis was used. A level of significance of $p<0.05$ was used, to ensure that all the items with even a weak correlation were identified.

Relationship with patients' perception of general health. Spearman's correlation coefficient for ranked data was determined to test for an association between each item and the subjective perception of overall general health. A significant association was accepted at Spearman's $\rho \geq 0.21(p<0.05)$.

Relationship with patients' perception of respiratory health. Spearman's correlation coefficient for ranked data was determined to compare each item with the subjective perception of respiratory health. A significant association was accepted at Spearman's $\rho \geq 0.21(p<0.05)$.

\section{Results}

\section{Item analysis}

Response rate. The response rate was analysed as a frequency distribution (table 2). This analysis was confined to 144 questions, since in eight items multiple response category scales were used. Of the 144 items, $17 \%$ had a positive response rate $\leq 20 \%$ (i.e. almost all patients responded "False") and 6\% had a positive response rate $\geq 80 \%$ (i.e. almost all patients responded "True"). Typical examples of questions with a positive response rate $\geq 20 \%$ were: "I think my treatment is not helping me much" (14\%); "I frequently forget which is the current month" $(8 \%)$; and "Because of my respiratory disease my family gives me less attention than usual" (7\%). Typical examples of items that were almost universally positive (i.e. response rate $>80 \%$ ) were: "Walking up hills makes me breathless" (88\%); "Because of breathlessness I am not picking up heavy things as I would like to" (90\%); and "Because of my respiratory disease I avoid crowded places" (84\%).

Age effect. Nineteen (13\%) items significantly correlated with age. Examples of these items included: "Picking up light things makes me breathless" $(\rho=0.23 ; p=0.02)$; "I believe exercising is not safe for me" $(\rho=0.31 ; p=0.004)$; and "I am too old to get any better" $(\rho=0.36 . p=0.0007)$.

Sex effect. An effect of sex was found in the responses to $25(16 \%)$ items including: "I have morning headache" $\left(\chi^{2}=5.7 ; \mathrm{p}=0.01\right)$; "I feel my getting better depends on doctors and nurses" $\left(\chi^{2}=7.3 ; \mathrm{p}=0.006\right)$; and "My chest trouble made me stop any kind of work" $\left(\chi^{2}=5.7 ; \mathrm{p}=\right.$ $0.01)$.

Disease effect. The number of questions with statistically different answers between COPD and kyphoscolitic patients was 15 (10\%). Examples included: "My cough and/or catarrh makes me avoid people" $\left(\chi^{2}=5.9\right.$; $\mathrm{p}=0.01)$; "My chest trouble makes a great difference to my life" $\left(\chi^{2}=6.6 ; \mathrm{p}=0.009\right)$; and "My illness is almost certainly a consequence of the life style I had" $\left(\chi^{2}=12.6\right.$; $\mathrm{p}=0.0004$ ).

Treatment effect. Responses to $28(18 \%)$ items were related to the treatment being received (either LTOT or HMV). Typical examples were: "Because of my breathlessness I am not taking a bath as I would like to" $\left(\chi^{2}=5.6 ; \mathrm{p}=0.01\right)$; "I get frightened or panic when I cannot get my breath" $\left(\chi^{2}=6.4: p=0.007\right)$; "I frequently repeat myself" $\left(\chi^{2}=5.8 ; \mathrm{p}=0.01\right)$.

Table 2. - Frequency distribution of the positive response rate to the 144 items

\begin{tabular}{lc}
\hline Positive response rate $\%$ & Items n (\%) \\
\hline $0-19$ & $24(17)$ \\
$20-39$ & $48(33)$ \\
$40-59$ & $47(33)$ \\
$60-79$ & $16(11)$ \\
$80-100$ & $9(6)$ \\
Total & $144(100)$ \\
\hline
\end{tabular}


Relationship with patients' perception of general health. Spearman's correlation coefficient for ranked data showed that $102(67 \%)$ items did not correlate with the subjective perception of general health at the preset threshold of $\mathrm{p}<$ 0.05 (corresponding to $\rho \geq 0.21$ ). Exam-ples included: "I sleep with frequent awaking" $(r=0.07 ; \mathrm{p}=0.9)$; "Hobbies and pastimes do not help me to feel any better" $(\rho=0.09$; $p=0.4$ ); and "Because of my respiratory disease I am not able to spend time with children" $(\rho=0.02 ; p=0.9)$.

Relationship with patients' perception of respiratory health. No correlation was found between overall perceived respiratory health and the response to $91(60 \%)$ items. Typical examples were: "Taking a bath makes me breathless" $(\rho=0.17 ; p<0.1)$. "Putting on my socks, stockings or shoes makes me breathless" $(\rho=0.11 ; p=0.3)$; and "People think I am different because I have got chest trouble" $(\rho=0.15 ; p=0.2)$.

\section{Multiple determinants of item response}

Some items were influenced by more than just one factor. To assess the level of multiple determinants of item response, the following groupings were analysed: age and/ or sex; disease and/or treatment; and general and/or respiratory health.

Age and/or sex effects. Seven items were influenced by both age and sex. Examples of these included: "My reactions are usually very slow"; and "Because of my respiratory disease my relationships with my family are very cold". In total, 37 items were influenced by age, sex or both.

Disease and/or treatment effects. Eight items were influenced by both disease and treatment type. Typical examples of the shared questions were: "My cough and/ or catarrh makes me avoid people"; "My chest trouble makes a great difference to my life"; and "I am too old to get any better". A total of 35 items were influenced by disease, treatment or both.

Items relating to general and/or respiratory health. A total of 74 items correlated with general health $(n=17)$, respiratory health $(n=20)$ or both $(n=37)$. Of the 74 items, 30 were related to one or more of age, sex, disease or treatment. This left 44 items that might be considered to be "core" items for CRF. Of these, two were responded to by $\geq 80 \%$ of patients and eight were responded to by $\leq 20 \%$. This left 34 items that correlated with global or respiratory health, were independent of age, sex, diagnosis and treatment and did not have floor or ceiling effects. Two of these items were retrospective (i.e. they asked about breathing troubles over the preceding year), whereas the other 32 were about the patient's respiratory state over the preceding few days. The two retrospective items were also unlike the other items in that they were concerned with the frequency of respiratory symptoms, whereas the other 32 items concerned activities of daily living or disturbances to wellbeing. Within the latter, eight were duplicates as they asked the patient the same question in two different ways. They largely concerned daily activities (e.g. "Doing house- work or light repairs around the house makes me breathless"/"Because of breathlessness I am not doing housework or light repairs around the house as I would like to"). In order to eliminate these duplicates, the item from each pair that had the better correlation with perceived health and/or resulted in a large percentage of patients responding positively was chosen. The other item from the pair was deleted.

\section{Principal components analysis of the Maugeri Founda- tion Respiratory Failure item set}

In order to examine the structure of the questionnaire, the remaining 28 items relating to the health of patients with CRF (hereafter referred to as the Maugeri Foundation Respiratory Failure item set (MRF-28) (see Appendix)) were submitted to principal components analysis. An orthogonal rotation based on Varimax was performed. In a 3factor solution, the total matrix sampling adequacy was 0.80 . Factor 1 accounted for $27 \%$ of the variance, factor 2 for $8 \%$ and factor 3 for $6 \%$. The first factor contained 11 items (loading value $>0.5$ ), all related to "daily activity": three to activities which made the patients breathless (e.g. washing themselves, getting dressed), and eight to activities that patients cannot perform as they would like to because of breathlessness (e.g. cooking, picking up light things, talking). The second factor comprised four items concerned with "cognitive function", i.e. memory and concentration. The third factor contained five items that could be designated under the label "invalidity". The remaining eight items had a loading $<0.5$ with any factor.

\section{Comparison of the Maugeri Foundation Respiratory Failure item set and existing measures}

To permit a comparison between responses to the items comprising the MRF-28 and other relevant measures of disease severity, a total score for the MRF-28 was obtained by giving a score of "1" for each positive response to an item and " 0 " for each negative response; the item scores were then summed and expressed as a percentage of 28 , which was the maximum possible score. Similar scores were also calculated for the three factors identified by principal components analysis (i.e. daily activity, cognitive function and invalidity). The distribution of scores for total MRF-28, the SGRQ and the SIP are shown in figure 1. The MRF-28 scores were normally distributed and covered the entire scaling range of the questionnaire. In contrast, the SGRQ scores covered $76 \%$ of its potential scaling range, and the SIP scores only $39 \%$ of its range. Similarly, the interquartile range for the MRF-28 was wider than that for the SGRQ or the SIP (fig. 1). The total score of the MRF-28 correlated well with the SGRQ and SIP, as illustrated in figures 2 and 3.

In order to further compare the performance of the 28item set with the existing questionnaires, multitrait, multimetric analysis was performed relating the questionnaire scores to a range of physiological variables and questionnaires for dyspnoea and mood (table 3). Overall, the pattern of the correlations obtained with the SGRQ and the MRF-28 were very similar and generally stronger than those obtained with the SIP. The validity of the 


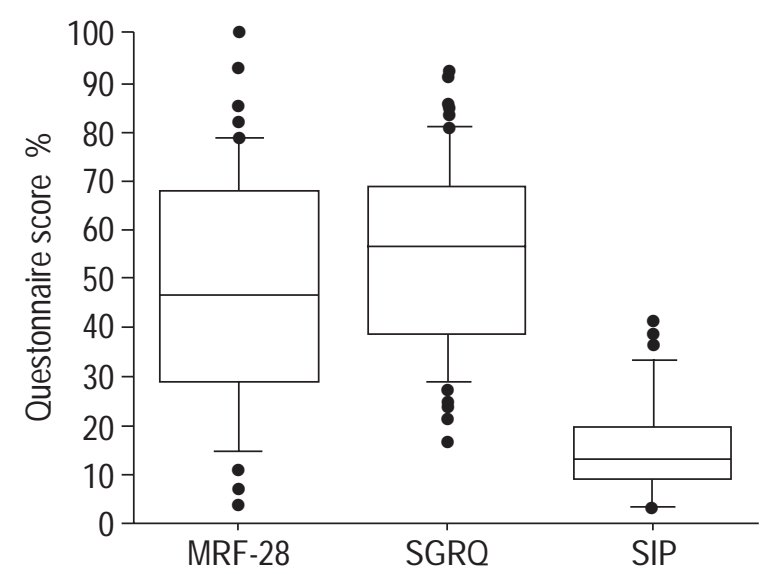

Fig. 1. - Box plots showing the distribution of scores as a percentage of total possible score for the Maugeri Foundation Respiratory Failure item set (MRF-28), the St George's Respiratory Questionnaire (SGRQ) and the Sickness Impact Profile (SIP). Median and 10th, 25th, 75th and 90th percentiles are shown. Points represent outliers.

MRF-28 was further tested by examining the relationship between its three specific components and reference measures of disease activity. Daily activity correlated with almost all measures, whether physiological, mood state or dyspnoea. Cognitive function correlated only with mood state, whilst invalidity correlated strongly with mood and also with dyspnoea, $6 \mathrm{MWD}$ and $\mathrm{Pa}_{\mathrm{a}} \mathrm{O}_{2}$ (table 4).

\section{Discussion}

This study identified a core set of items relevant to patients with CRF that are related to global impaired health, do not have floor or ceiling effects and appear to be independent of age, sex, diagnosis and treatment. As might have been expected, it identified a number of items associated with disability due to breathlessness in daily life. In addition, it identified, for the first time, two other components that appear to be relatively discrete. The first

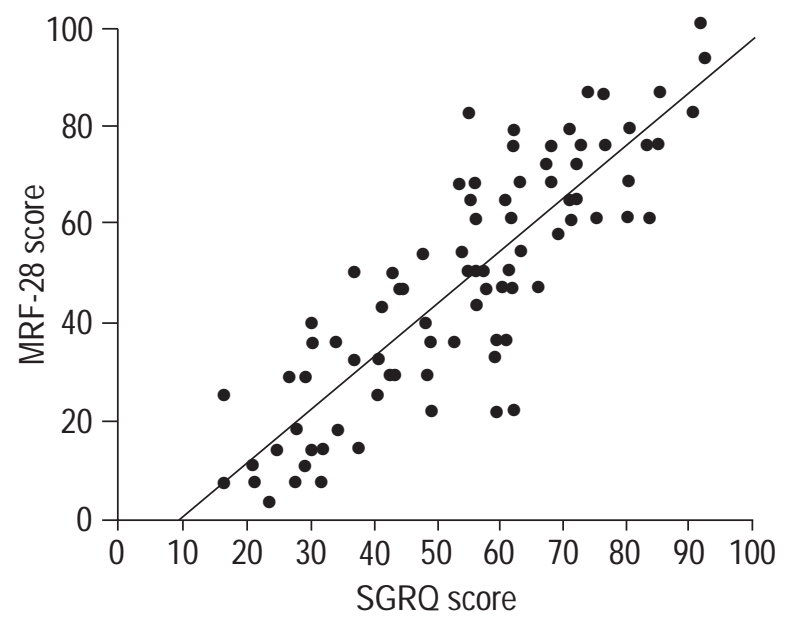

Fig. 2. - Correlation between the scores as a percentage of total possible score for the Maugeri Foundation Respiratory Failure item set (MRF-28) and the St George's Respiratory Questionnaire (SGRQ) in patients with chronic respiratory failure. $\mathrm{r}=0.86, \mathrm{p}<0.0001$.

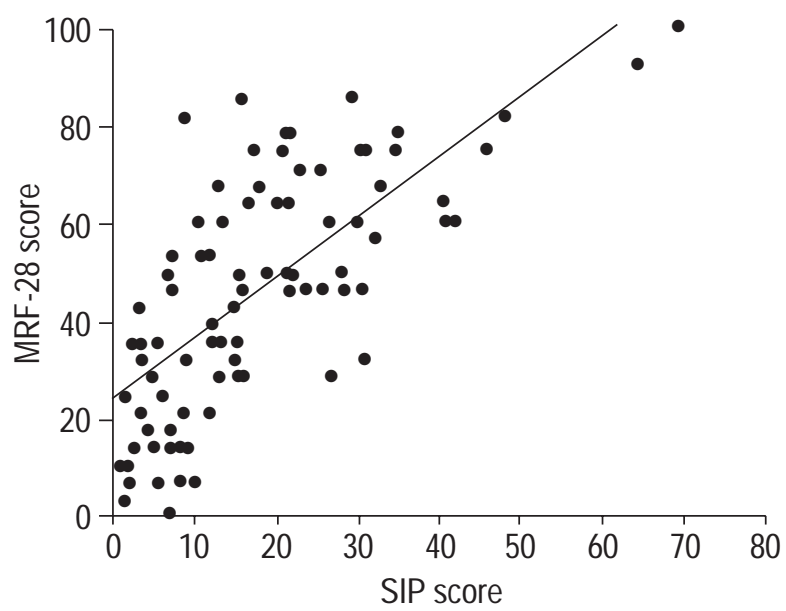

Fig. 3. - Correlation between the scores as a percentage of total possible score for the Maugeri Foundation Respiratory Failure item set (MRF-28) and the Sickness Impact Profile (SIP) in patients with chronic respiratory failure. $\mathrm{r}=0.70, \mathrm{p}<0.0001$.

of these is "cognitive function". Previous work has shown that patients with severe hypoxia appear to have areas of impaired cognitive function compared to normoxic subjects $[33,34]$, but those observations were made using laboratory measures of psychological function. The unique feature of the items identified in this study is that they relate to the effect of impaired cognitive function on daily life. The second component of impaired health identified by this study is the grouping of items that have been termed "invalidity". This term was selected, because the highest loading item in this factor in the principle components analysis was "Because of my lung disease I have become an invalid". Inspection of the other items in this component reveals that they are related to an inability of patients to exert themselves, the experience of social

Table 3. - Correlations (Spearman) between total scores of the Maugeri Foundation Respiratory Failure item set (MRF-28), St George's Respiratory Questionnaire (SG-RQ) and Sickness Impact Profile (SIP) and measures of physiological function, mood and dyspnoea

\begin{tabular}{|c|c|c|c|c|c|c|}
\hline & \multicolumn{2}{|c|}{ MRF-28 } & \multicolumn{2}{|c|}{ SGRQ } & \multicolumn{2}{|c|}{ SIP } \\
\hline & $\mathrm{r}$ & p-value & $\mathrm{r}$ & p-value & $\mathrm{r}$ & $\mathrm{p}$-value \\
\hline FEV1 \% pred & 0.18 & NS & 0.22 & NS & 0.01 & NS \\
\hline $\mathrm{O}_{2}$ rest & 0.32 & 0.004 & 0.34 & 0.0003 & 0.20 & NS \\
\hline $\mathrm{O}_{2}$ exercise & 0.29 & 0.007 & 0.30 & 0.005 & 0.18 & NS \\
\hline 6MWD & 0.32 & 0.003 & 0.28 & 0.01 & 0.26 & NS \\
\hline $\begin{array}{l}P \mathrm{a}, \mathrm{O}_{2} \\
\text { (room air) }\end{array}$ & 0.44 & 0.0007 & 0.48 & 0.0002 & 0.46 & 0.0003 \\
\hline $\begin{array}{l}P \mathrm{a}, \mathrm{CO}_{2} \\
\text { (room air) }\end{array}$ & 0.18 & NS & 0.17 & NS & 0.04 & NS \\
\hline Depression & 0.79 & 0.0001 & 0.72 & 0.0001 & 0.71 & 0.0001 \\
\hline Anxiety & 0.45 & 0.0001 & 0.40 & 0.0001 & 0.47 & 0.0001 \\
\hline $\begin{array}{l}\text { MRC dysp- } \\
\text { noea score }\end{array}$ & 0.44 & 0.003 & 0.46 & 0.002 & 0.40 & 0.004 \\
\hline
\end{tabular}

FEV1: forced expiratory volume in one second; $\mathrm{O}_{2}$ rest: oxygen flow used by patients at rest; $\mathrm{O}_{2}$ exercise: oxygen flow during exercise; 6MWD: 6-min walking distance; $\mathrm{Pa}_{\mathrm{a}} \mathrm{O}_{2}$ (room air): arterial oxygen tension measured breathing room air; $P \mathrm{a}, \mathrm{CO}_{2}$ (room air): arterial carbon dioxide tension measured breathing room air; MRC: Medical Research Council; Ns: not significant at $\mathrm{p}>0.01$. 
Table 4. - Correlations (Spearman) between scores for the three principal components of the Maugeri Foundation Respiratory Failure item set (daily activity, cognitive function and invalidity) and measures of physiological function, mood and dyspnoea

\begin{tabular}{|c|c|c|c|c|c|c|}
\hline & \multicolumn{2}{|c|}{$\begin{array}{l}\text { Daily } \\
\text { activity }\end{array}$} & \multicolumn{2}{|c|}{$\begin{array}{l}\text { Cognitive } \\
\text { function }\end{array}$} & \multicolumn{2}{|c|}{ Invalidity } \\
\hline & $\mathrm{r}$ & $\mathrm{p}$-value & $\mathrm{r}$ & $\mathrm{p}$-value & $\mathrm{r}$ & p-value \\
\hline FEV1 \% pred & 0.18 & NS & 0.05 & NS & 0.15 & NS \\
\hline $\mathrm{O}_{2}$ rest & 0.33 & 0.003 & 0.10 & NS & 0.21 & NS \\
\hline $\mathrm{O}_{2}$ exercise & 0.35 & 0.001 & 0.13 & NS & 0.19 & NS \\
\hline 6MWD & 0.32 & 0.004 & 0.07 & NS & 0.25 & 0.02 \\
\hline $\begin{array}{l}P \mathrm{~Pa}, \mathrm{O}_{2} \\
\quad \text { (room air) }\end{array}$ & 0.33 & 0.01 & 0.15 & NS & 0.39 & 0.003 \\
\hline $\begin{array}{l}\mathrm{Pa}, \mathrm{CO}_{2} \\
\quad \text { (room air) }\end{array}$ & 0.23 & NS & 0.04 & NS & 0.04 & NS \\
\hline Depression & 0.62 & 0.0001 & 0.50 & 0.0001 & 0.64 & 0.0001 \\
\hline Anxiety & 0.31 & 0.002 & 0.43 & 0.0001 & 0.34 & 0.0009 \\
\hline $\begin{array}{l}\text { MRC dysp- } \\
\text { noea score }\end{array}$ & 0.42 & 0.0006 & 0.23 & NS & 0.32 & 0.01 \\
\hline
\end{tabular}

FEV1: forced expiratory volume in one second; $\mathrm{O}_{2}$ rest: oxygen flow used by patients at rest; $\mathrm{O}_{2}$ exercise: oxygen flow during exercise; 6MWD: 6-min walking distance; $\mathrm{Pa}_{\mathrm{a}} \mathrm{O}_{2}$ (room air): arterial oxygen tension measured breathing room air; $P \mathrm{a}, \mathrm{CO}_{2}$ (room air): arterial carbon dioxide tension measure breathing room air; MRC: Medical Research Council; ns: not significant at $\mathrm{p}>0.01$.

isolation or dependency on others. Similar items may be found in an isolated manner in other questionnaires, but this study has shown that a sense of general invalidity appears to be a fairly specific component of ill health in severe respiratory failure.

Several "QoL" questionnaires have been used to assess the impact of CRF on patients' daily life and wellbeing. Some are general measures, others disease-specific. None were specifically designed for CRF. The SIP and the SF-36 have been shown to have discriminant properties in patients with chronic airflow limitation, but were developed to quantify impairment of health in a wide range of diseases, and so the proportion of their content that is relevant to CRF may be low. Furthermore, the distribution of SIP scores in patients with COPD (which are low, i.e. little apparent health impairment) suggests that the SIP may be more responsive to deterioration than to improvement in health in such patients [6]. This could be a major limitation when attempting to assess the response to treatment. The two studies which used the SF-36 in very severe patients $[15,16]$ showed a mixed pattern of scores for its different components. For some components, the scores were no different from, or even indicated less impairment than, those of normal subjects or patients with other chronic diseases. In other components, the scores were higher than in other diseases. This may reflect differential effects of severe respiratory failure on areas of impaired health or imply that the SF-36 is not appropriate for such patients. In contrast to generic instruments, disease-specific questionnaires have been developed to provide instruments with a high level of sensitivity to changes in health. The CRQ and the SGRQ are the two most widely used disease-specific questionnaires in chronic airflow limitation. They have also been used in the most severe patients. However, CRF can be present not only in COPD but also in other diseases such as kyphoscoliosis. In view of the limitations of existing questionnaires, this study set out to identify a core set of items important in patients with CRF.

The process of validating a new questionnaire is complex. The first step is often to correlate it with existing measures. This was done by comparing the new 28respiratory failure item set with the SGRQ and the SIP (figs. 2 and 3). The correlation between the MRF-28 and the SGRQ was high $(\mathrm{r}=0.86)$. This was not due to a large number of items being shared between the MRF-28 and the SGRQ since only two of the 28 MRF-28 items are similar to those of the SGRQ. The correlations illustrated in figures 2 and 3 show that all three questionnaires appear to address similar aspects of impaired health in these CRF patients, but their properties are not identical since neither regression line passes through the origin. As this kind of comparison gives no information concerning metric properties, to test the convergence validity of the new 28 item set more intensively, a multitrait multimetric analysis was used. This showed that the MRF-28 behaved in a similar manner to the other questionnaires in terms of its relationship to reference measures of disease activity, disability and impaired mood. In addition, the new instrument's individual components appeared to show some specificity. Daily activity correlated with all measures except FEV1. This is unsurprising since FEV1 is known to be a poor correlate of impaired health in COPD. Furthermore, some of these patients had kyphoscoliosis and FEV1 may, therefore, not be a reliable estimate of impaired lung function. Impaired cognitive function related only to impaired mood. This association was expected, although the nature of this relationship is not understood. It is possible that impaired mood may result in lower cognitive function or that an awareness of poor function impairs the patient's mood. The correlation between cognitive function and $\mathrm{Pa}, \mathrm{O}_{2}$ was low, but this was unsurprising. Previous studies using sophisticated psychometric instruments failed to find any strong correlations between $\mathrm{Pa}, \mathrm{O}_{2}$ and impaired higher cerebral function [33]. The invalidity component reflected impaired mood very strongly and also correlated with $\mathrm{Pa}, \mathrm{O}_{2}$. This latter correlation appears too strong to have occurred by chance and may be due to an effect of hypoxia on activity, leading to social isolation and dependency upon others.

Health status questionnaires continue to proliferate. This raises the question of the utility of this new 28 item set since it appears to behave in a similar manner to existing instruments. In addressing this question, it can be argued that this study was the first to examine, specifically, health impairment due to CRF. At one level, the study shows that existing questionnaires do have some validity as measures of impaired health in this group of patients since they appear to be measuring approximately the same thing as the new item set. However, the MRF-28 does have several advantages over the existing measures: 1) It is the first questionnaire specifically developed for use in CRF; 2) in contrast to the SGRQ, its items were selected to be applicable to patients with both obstructive and restrictive diseases; 3$)$ it contains fewer items $(n=28)$ than the SGRQ $(n=50)$ or the SIP $(n=136)$, and consequently is less-time consuming to administer; 4) it defines two areas of health impairment due to CRF not identified by the SGRQ or the 
CRQ; and 5) the distribution of scores for the MRF-28 is wider than that for either the SGRQ or the SIP (fig. 1): its interquartile range was $30 \%$ wider than that of the SGRQ and $116 \%$ wider than that of the SIP. This suggests that the MRF-28 may be able to discriminate between different levels of impaired health better than existing questionnaires. As a result it may also detect changes in health more sensitively than existing measures.

In conclusion, this study has formally identified items specifically related to impaired health in respiratory failure. It has characterized two new fairly well-defined areas of impaired health in severe respiratory disease in addition to effects on physical activity. Its measurement properties suggest that it may discriminate between patients with different levels of impaired health due to respiratory failure better than existing questionnaires. Sensitivity to change can only be tested by longitudinal studies. In view of the nature of CRF, such studies would have to be of sufficient length to detect clinically meaningful changes in health. The minimum follow-up period for such studies would need to be $1 \mathrm{yr}$. Such a project is underway in a multinational study [35].

This questionnaire was developed primarily for use in patients with respiratory failure secondary to pulmonary or chest wall diseases. If it were to be used in patients with neuromuscular disease, validation in such patients would be needed.

\section{Appendix: the "Maugeri Foundation" Respiratory Failure item set (MRF-28), as subdivided by principal components analysis}

Factor 1-daily activities

Washing myself (face, neck, etc.) usually makes me feel breathless

Combing my hair or shaving myself usually makes me feel breathless

Getting dressed usually makes me feel breathless

Because of my lung disease, I am unable to shower as I would like to

Because of my lung disease, I cannot put on my socks, stockings or shoes as I would like to

Because of my lung disease, I am not able to cook as I would like to

Because of my lung disease, I cannot do housework or light repairs around the house as I would like to

Because of my lung disease, when I need to, I cannot bend over as I would like to

Because of my lung disease, when I need to, I cannot pick up light things as I would like to

Because of my lung disease, I cannot play with children as I would like to

Because of my lung disease, I cannot talk as much as I would like to

\section{Factor 2-cognitive function}

I forget names now more than I used to

I am very absent minded

When I am talking, I often forget what I wanted to say Even when something interests me very much I cannot maintain concentration as long as I would like to

\section{Factor 3-invalidity}

Because of my lung disease, I have become an invalid Because of my lung disease, everything seems too much of an effort

Because of my lung disease, I go out to see friends or acquaintances less than usual

Because of my lung disease, I spend much more time alone Because of my lung disease, when I am outside I feel I need to have someone with me

Items with a correlation coefficient $<0.5$ with any factor

I feel tired in the morning

I feel unrefreshed in the morning

I feel irritable during the daytime

I think my respiratory problem is incurable

Because of my respiratory disease I feel that I am a burden to my family

Because of my respiratory disease I avoid going shopping Standing up makes me breathless

My respiratory device interferes with my life a lot

Acknowledgements. The authors thank G. Omarini, P. Omarini, D. Sacco and R. Allpress for their most valuable technical assistance.

The "Quality of Life in Chronic Respiratory Failure Group" also includes: N. Ambrosino, G. Bruletti, R Corsico, V. Cuorno, D. Errera, M. Grandi, F. Ioli, C. Logroscino, G. Majani, A. Meriggi, M. Naimo, M. Neri, A. Quadri, C. Rampulla, A. Terazzi, S. Zaccaria.

\section{References}

1. Pierson DJ. Respiratory failure: introduction and overview. In: Pierson DJ, Kacmarek RM, eds. Foundation of Respiratory Care. New York, Churchill Livingstone, 1992; pp. 295-310.

2. Williams SJ. Chronic respiratory illness and disability; a critical review of the psychosocial literature. Soc Sci Med 1989; 28: 791-803.

3. Spencer S, Daniels J, Jones PW. Spirometry and quality of life in poorly reversible COPD. Am J Respir Crit Care Med 1996; 153: A323.

4. Jones PW, Quirk FH, Baveystock CM. Why quality of life should be used in the treatment of patients with respiratory illness. Monaldi Arch Chest Dis 1994; 49: 79-82.

5. Guyatt G. Measuring health status in chronic airflow limitation. Eur Respir J 1988; 1: 560-564.

6. Jones PW. Quality of life measurement for patients with diseases of the airways. Thorax 1991; 46: 676-682.

7. Bergner M, Bobbit RA, Carter WB, Gilson BS. The Sickness Impact Profile: development and final revision of a health status measure. Med Care 1981; 19: 787-805.

8. Stewart AL, Hays RD, Ware JE. The MOS Short Form General Health Survey: reliability and validity in a patient population. Med Care 1988; 26: 724-732.

9. Hunt SM, McEwen J, McKenna SP. Measuring Health Status. 1st Edn. Beckenham, Kent, Croom Helm, 1986.

10. Jones PW, Baveystock CM, Littlejohns P. Relationships between general health measured with the Sickness Impact Profile and respiratory symptoms, physiological 
measures and mood in patients with chronic airflow limitation. Am Rev Respir Dis 1989; 140: 1538-1543.

11. Williams SJ, Bury MR. Impairment, disability and handicap in chronic respiratory illness. Soc Sci Med 1989; 29: 609-616.

12. McSweeny JA, Grant I, Heaton RK, Adams KM, Timms RM. Life quality of patients with chronic obstructive pulmonary disease. Arch Intem Med 1982; 142: 473-478.

13. Prigatano GP, Wright EC, Levin D. Quality of life and its predictors in patients with mild hypoxemia and chronic obstructive pulmonary disease. Arch Intem Med 1984; 144: 1613-1619.

14. Okubadejo AA, Jones PW, Wedzicha JA. Quality of life in patients with chronic obstructive disease and severe hypoxaemia. Thorax 1996; 51: 44-47.

15. Simonds AK, Elliott MW. Outcome of domiciliary nasal intermittent positive pressure ventilation in restrictive and obstructive disorders. Thorax 1995; 50: 604-609.

16. Smith IE, Shneerson JM. A progressive care programme for prolonged ventilatory failure: analysis of outcome. $\mathrm{Br}$ $J$ Anaesth 1995; 75: 399-404.

17. Crockett AJ, Cranston JM, Moss M, Alpers JH. The MOS SF-36 health survey questionnaire in severe chronic airflow limitation: comparison with the Nottingham Health Profile. Qual Life Res 1996; 5: 330-338.

18. Tsukino M, Nishimura K, Ikeda A, Koyama H, Mishima $\mathrm{M}$, Izumi T. Physiologic factors that determine the healthrelated quality of life in patients with COPD. Chest 1996; 110: 896-903.

19. Ferrer M, Alonso J, Morera J, et al. Chronic obstructive pulmonary disease stage and health-related quality of life. Ann Intern Med 1997; 127: 1072-1079.

20. Guyatt GH, Berman LB, Towsend M, Pudsley SO, Chambers LW. A measure of quality of life for clinical trials in chronic lung disease. Thorax 1987; 42: 773-778.

21. Jones PW, Quirk FH, Baveystock CM, Littlejohns P. A self-complete measure for chronic airflow limitation the St George's Respiratory Questionnaire. Am Rev Respir Dis 1992; 145: 1321-1327.

22. Wegner RE, Jörres RA, Kirsten DK, Magnussen H. Factor analysis of exercise capacity, dyspnoea ratings and lung function in patients with severe COPD. Eur Respir $J$ 1994; 7: 725-729.

23. Meecham Jones DJ, Paul EA, Jones PW, Wedzicha JA. Nasal pressure support ventilation plus oxygen compared with oxygen therapy alone in hypercapnic COPD. $A m J$ Respir Crit Care Med 1995; 152: 538-544.

24. Kinsman RA, Jones NF, Matus I, Shum RA. Patient variables supporting chronic illness: a scale for measuring attitudes towards respiratory illness and hospitalisation. $J$ Nerv Ment Dis 1976; 163: 159-165.

25. Quanjer PH. Standardised lung function testing. Bull Eur Physiopathol Respir 1983; 40: 1203-1207.

26. McGavin CR, Gupta SP, McHardy GJR. Twelve-minute walking test for assessing disability in chronic bronchitis. BMJ 1976; 1: 822-823.

27. Butland RJ, Pang J, Gross ER, Woodcock AA, Geddes DM. Two-, six-, and 12 minute walking tests in respiratory disease. BMJ 1982; 284: 1607-1608.

28. Guyatt GH, Pugsley SO, Sullivan MJ, et al. Effect of encouragement on walking test performance. Thorax 1984; 39: 818-822.

29. Knox AJ, Morrison JFJ, Muers MF. Reproducibility of walking test results in chronic obstructive airways disease. Thorax 1988; 43: 388-392.

30. Medical Research Council, Committee on the aetiology of chronic bronchitis. Standardised questionnaire on respiratory symptoms. BMJ 1960; 2: 1665.

31. Bertolotti G, Zotti AM. A computerised approach to cognitive behavioural assessment: an introduction to CBA2.0 primary scales. J Behav Ther Exp Psychiatry 1990; 21: 21-27.

32. Spielberger CD, Gorsuch RL, Lushene RE. The StateTrait inventory (STAI) test manual for form X. Palo Alto, Consulting Psychologist Press, 1970.

33. Grant I, Prigatano GP, Heaton RK, McSweeny AJ, Wright EC, Adams KM. Progressive neuropsychologic impairment and hypoxemia. Relationship in chronic obstructive pulmonary disease. Arch Gen Psychiatry 1987; 44: 999_ 1006.

34. Fix AJ, Golden CJ, Daughton D, Kass I, Bell CW. Neuropsychological deficits among patients with chronic obstructive pulmonary disease. Int J Neurosci 1982; 16 : 99-105.

35. Carone M, Donner CF, Jones PW, on behalf of the QuEST Group. The quality of life evaluation and survival trial (QuEST): a multinational study to evaluate impaired health and natural history of chronic respiratory failure. Eur Respir J 1998; 12: Suppl. 28, 296s. 